\title{
Características químicas e densidade global de um latossolo vermelho eutróferrico cultivado com plantas de cobertura em Toledo-PR
}

\author{
Chemical characteristics and global density of an eutroferric red \\ latosol cultivated with cover crops in Toledo District, Parana State
}

\author{
Márcia de Holanda Nozaki ${ }^{*}$; Maicon Vendrúscolo ${ }^{2}$
}

\begin{abstract}
Resumo
A expansão da fronteira agrícola através de desmatamentos, adoção de mecanização intensiva e uso de práticas de manejo inadequadas, tem promovido alterações nas propriedades físicas, químicas e biológicas do solo, resultando em processos de degradação, reduzindo desta maneira a produtividade. Com base no exposto, o objetivo do trabalho foi avaliar características químicas e densidade global de um Latossolo Vermelho Eutróferrico, da área experimental da Fazenda da Pontifícia Universidade Católica do Paraná, Campus Toledo, sob tratamentos do milheto (Pennisetum glaucum) e da ervilhaca peluda (Vicia villosa) como plantas de cobertura. O delineamento utilizado foi o de blocos ao acaso com quatro repetições, em que os tratamentos foram: milheto, ervilhaca peluda e testemunha (vegetação espontânea). As avaliações foram de produção de massa seca, na qual o milheto apresentou maior quantidade (7.07 $\left.\mathrm{Mg} \mathrm{ha}^{1}\right)$; densidade global do solo, em que a testemunha apresentou menor valor, enquanto a ervilhaca peluda teve o maior; densidade populacional de plantas daninhas, que foi maior no tratamento testemunha; química do solo, na qual tanto a ervilhaca peluda quanto o milheto apresentaram bons resultados comparados com a testemunha, diferenciando-se em alguns nutrientes, como fósforo, potássio e nitrogênio.

Palavras-chave: Adubação verde, Pennisetum glaucum, Vicia villosa
\end{abstract}

\begin{abstract}
The expansion of agricultural frontier through deforestation, adoption of mechanization and intensive use of inappropriate management practices, has promoted changes in the physical, chemical and biological properties of the soil, resulting in degradation processes, thus reducing productivity. Based on this, the objective the work was to evaluate the chemical characteristics and the global density of an Eutroferric Red Latosol of the experimental area of the Parana Catholic University, Toledo Campus. The experimental design used was casualized blocks with four replicates, in which the treatments were: millet, hairy vetch and control (spontaneous vegetation). The evaluations were: dry mass production, with the highest amount for millet $\left(7.07 \mathrm{Mg} \mathrm{ha}^{1}\right)$, global soil density in which the lowest value was under control and the highest in hairy vetch; density of weeds population in which the control treatment had the highest value on; soil chemical characteristics, in which both hairy vetch and millet presented higher results compared to the control, being different in some nutrients, such as phosphorus, potassium and nitrogen.
\end{abstract}

Key words: Green manure, Pennisetum glaucum, Vicia villosa

\footnotetext{
${ }^{1}$ Professora Doutora do curso de graduação em Agronomia da Pontifícia Universidade Católica do Paraná, Campus Toledo, PR. E-mail: marcia.nozaki@pucpr.br

2 Engenheiro Agrônomo pela Pontifícia Universidade Católica do Paraná. E-mail: bagrinho_ma@hotmail.com

* Autor para correspondência
} 


\section{Introdução}

Nas duas últimas décadas, foram realizados diversos trabalhos com plantas de cobertura de solo no outono/inverno, tanto no Brasil como em outros países, procurando-se caracterizar a decomposição e a liberação de nitrogênio $(\mathrm{N})$ de seus resíduos culturais (AITA; GIACOMINI, 2003). O acentuado aumento na produção de uréia no país, fez com que este produto sintético se tornasse a principal fonte de $\mathrm{N}$ na agricultura brasileira, representando $60 \%$ da produção nacional de fertilizantes nitrogenados (PERIN, 2005).

Neste contexto, e considerando-se a competitividade do mercado mundial, torna-se necessário reduzir os custos de produção, aumentar a produtividade e proteger o meio ambiente em todos os setores agrícolas. Essa preocupação é uma realidade para a maior parte dos agricultores e técnicos (DUARTE, 2006). De acordo com estimativa da FEBRAPDP (Federação Brasileira de Plantio Direto na Palha), a área nacional cultivada em plantio direto de 1992/93 a 2003/04 safra verão/ safrinha/inverno cresceu mais de $1.000 \%$, chegando a, aproximadamente, 22 milhões de hectares. $\mathrm{O}$ Paraná apresentava, em 2001, uma área de quase cinco milhões de hectares de plantio direto, sendo a maior entre os demais Estados (FEBRAPDP, 2004).

A adubação verde vem como uma alternativa neste processo e consiste na incorporação ao solo de massa produzida por plantas cultivadas, ricas em nutrientes, objetivando melhorar as condições físicas, químicas e biológicas do solo, com vistas ao aumento da fertilidade e conservação do solo. Dentre os benefícios da adubação verde no solo, citam-se a retenção de umidade, a melhoria da fertilidade, diminuição na variação da temperatura, descompactação, estruturação e melhoria da aeração, fixação do nitrogênio da atmosfera, intensificação da atividade biológica e suprimento de matéria orgânica. Além destes, tem-se os efeitos alelopáticos contra pragas e doenças, e a redução da infestação de plantas daninhas (OLIVEIRA et al., 1993).
$\mathrm{Na}$ adubação verde, não existe uma planta ideal, portanto, a depender da espécie utilizada e das condições de cultivo, existem vantagens e desvantagens inerentes a cada uma delas, sendo então necessário levantar informações sobre as plantas envolvidas e sobre o modo de utilização antes da escolha (NEGRINI, 2007).

Estima-se que, atualmente, o milheto esteja sendo utilizado em dois milhões de hectares para o plantio direto, em áreas do Cerrado do CentroOeste. No Brasil, o milheto foi introduzido como espécie forrageira em 1929 no Rio Grande do Sul (ARAÚJO apud SOARES, 2005).

A ervilhaca, pela capacidade de fixar o $\mathrm{N}$ atmosférico, apresenta elevado potencial de fornecimento de $\mathrm{N}$ ao milho, embora seus resíduos culturais sejam rapidamente decompostos e, portanto, pouco eficientes no que concerne à proteção do solo contra os agentes erosivos (OHLAND et al., 2004).

O presente trabalho tem por objetivos avaliar alterações da densidade global e de atributos químicos de um Latossolo Vermelho Eutróferrico submetido ao cultivo com milheto e ervilhacapeluda como plantas de cobertura.

\section{Material e Métodos}

O trabalho foi realizado na área experimental da fazenda da Pontifícia Universidade Católica do Paraná (PUCPR), Campus Toledo, localizada nas

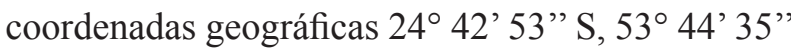
$\mathrm{W}$; e a $574 \mathrm{~m}$ em relação ao nível do mar (SIMEPAR, 2008). O solo de textura argilosa foi classificado como Latossolo Vermelho Eutroférrico típico (EMBRAPA, 2006) e a área vem sendo conduzida sob sistema de plantio direto por aproximadamente vinte anos.

O delineamento experimental utilizado foi em blocos ao acaso, com quatro repetições. Após preparo convencional da área, foram implantados os adubos verdes, ervilhaca peluda e milheto, além da 
testemunha (vegetação espontânea). Cada parcela tinha as dimensões de 3,5 $\mathrm{m}$ de largura por 4,0 m de comprimento. Tanto o milheto quanto a ervilhaca - peluda foram semeados em espaçamento de 0,5 $\mathrm{m}$ com aproximadamente 20 sementes por metro linear. O trabalho teve início no dia 26 de março de 2008 e aos 100 dias após o plantio (DAP), realizouse a dessecação das plantas nos tratamentos com glifosato $\left(3 \mathrm{~L} \mathrm{ha}^{-1}\right)$. No caso do milheto, houve a necessidade de incorporação, 30 dias após, com enxada.

Antes da dessecação, em pleno florescimento, foram retiradas amostras da parte aérea das culturas do milheto, da ervilhaca-peluda e da testemunha (vegetação espontânea), utilizando uma armação metálica de $0,25 \mathrm{~m}^{2}(0,50 \times 0,50 \mathrm{~m})$, lançada ao acaso em dois pontos por parcelas. As amostras foram secas em estufa de ar forçado a $55^{\circ} \mathrm{C}$, durante 72 horas, para a determinação da massa seca por hectare, produzida por cada cultura na superfície do solo.

Para determinação da densidade global utilizouse o método do anel volumétrico (EMBRAPA, 1997). As amostras de solo indeformadas foram coletadas em duas camadas (0-10 e 10-20 cm), obtidas com anéis volumétricos de $5 \mathrm{~cm}$ de altura por $5 \mathrm{~cm}$ de diâmetro $\left(98,175 \mathrm{~cm}^{3}\right)$. Após coletadas e preparadas em laboratório, foram secas em estufa a $105^{\circ} \mathrm{C}$ até obtenção do peso constante. A razão entre a massa do solo seco (Ms) e o volume do anel $(\mathrm{Vc})$ representando a densidade do solo foi expressa em gramas por centímetro cúbico $\left(\mathrm{kg} \mathrm{cm}^{-3}\right)$

A densidade populacional de plantas daninhas foi feita aos 130, 160 e 190 dias após a implantação do experimento. A avaliação foi realizada lançandose aleatoriamente, duas vezes em cada parcela, um quadro metálico com área de $0,25 \mathrm{~m}^{2}(0,50 \times 0,50 \mathrm{~m})$. $\mathrm{O}$ procedimento incluiu a contagem das plantas daninhas presentes na amostra, a determinação da densidade populacional na área e a identificação das plantas invasoras.

Antes do experimento foi realizada a análise química do solo, cujos dados são apresentados na (Tabela 1). Foram coletadas amostras de solo nas linhas e entrelinhas das culturas, nas profundidades de $0-10 \mathrm{~cm}$ e $10-20 \mathrm{~cm}$, com auxílio de um trado do tipo calador, compreendendo cinco sub-amostras de cada parcela, as quais foram posteriormente homogeneizadas formando uma amostra de cada parcela. Essas amostras foram retiradas aos 146 dias após a implantação do experimento, quando os resíduos vegetais estavam no início de sua decomposição.

Tabela 1. Análise química do solo antes da implantação do experimento, com profundidade $00-10 \mathrm{~cm}$.

\begin{tabular}{|c|c|c|c|c|c|c|c|c|}
\hline \multirow{3}{*}{ Macronutrientes } & $P$ & M.O & pH & $\mathbf{H}+\mathbf{A} \mathbf{l}^{3+}$ & $\mathrm{Ca}^{2+}$ & $\mathbf{A l}^{3+}$ & $\mathbf{M g}^{2+}$ & $\mathbf{K}^{+}$ \\
\hline & $\mathrm{mg} \mathrm{dm}{ }^{3}$ & $\mathrm{~g} \mathrm{dm}^{3}$ & ----- & 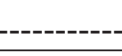 & $--\mathrm{Cm}$ & & & \\
\hline & 24,00 & 28,47 & 5,40 & 4,61 & 8,86 & 0,00 & 4,06 & 0,40 \\
\hline \multirow[b]{2}{*}{ Micronutrientes } & $\mathrm{Cu}$ & $\mathbf{Z n}$ & $\mathrm{Fe}$ & Mn & & & & \\
\hline & 3,90 & 4,60 & $\begin{array}{l}\mathrm{dm}^{3}-- \\
39,00\end{array}$ & 100,00 & & & & \\
\hline
\end{tabular}

(') Solução extratora de Mehlich-1; $\left({ }^{2}\right)$ extraído com solução de KCl - Walkey Black; $\left({ }^{3}\right) \mathrm{H}+\mathrm{Al}$ Tampão SMP - S (SO4) ${ }^{2-}$ e $\left({ }^{4}\right)$ determinado com solução de $\mathrm{CaCl}_{2} 0,01$ mol.L-1 .

Laboratório Coodetec - Responsável técnico: Mário Cesar Ferreira Godinho

As amostras coletadas e armazenadas em sacos plásticos, devidamente identificadas, foram posteriormente encaminhadas para o laboratório da Fundação para o Desenvolvimento Científico e Tecnológico de Toledo (FUNTEC). Com esse material foram feitas as seguintes análises: $\mathrm{pH}$, M.O., P, K, Ca, Mg, Al e H+Al; Cu, Zn, Fe e Mn (IAPAR, 1991). 
As variáveis de produção de massa seca, densidade populacional de plantas daninhas e densidade global de solo foram avaliadas através de análise de variância e as médias foram comparadas pelo teste de Tukey a $5 \%$ de probabilidade $(\mathrm{P}<$ 0,05) (SAS, 2006).

\section{Resultados e Discussão}

Com relação à produção de massa seca (MS), verifica-se que houve diferença significativa para a cultura do milheto, que proporcionou maior quantidade de massa seca do que os outros tratamentos testados (Tabela 2). Esta diferença devese, provavelmente, ao fato do milheto apresentar maior quantidade de haste e talos em relação à ervilhaca que, por sua vez, possui maior quantidade de folhas. Vale destacar, entretanto, que os resíduos do milheto permaneceram por maior tempo, ou seja, sua decomposição foi lenta quando comparado com a ervilhaca peluda, que teve rápida decomposição.

Tabela 2. Resultados médios para produção de massa seca nos tratamentos avaliados.

\begin{tabular}{cc}
\hline Espécie & Produção de Massa Seca * $\left(\right.$ Mg.ha $\left.^{-1}\right)$ \\
\hline Milheto & $7,07 \mathrm{a}$ \\
Testemunha & $2,68 \mathrm{~b}$ \\
Ervilhaca & $2,55 \mathrm{~b}$ \\
CV (\%) & 26,0 \\
\hline
\end{tabular}

* Médias seguidas pela mesma letra na coluna, não diferem entre si pelo teste de Tukey a 5\%.

Alenta decomposição do milheto está relacionada ao alto teor de lignina e alta relação $\mathrm{C} / \mathrm{N}$ dos resíduos, em torno de 26 . A relação $\mathrm{C} / \mathrm{N}$ da ervilhaca é em torno de 19, o que torna sua decomposição mais rápida (AITA et al., 2004). Para a vegetação espontânea, Moreira e Siqueira (2002) encontrou relação $\mathrm{C} / \mathrm{N}>25$. Valores altos da relação $\mathrm{C} / \mathrm{N}$ favorecem a imobilização do nitrogênio, podendo haver período temporário de deficiência do mesmo.

Para o milheto, obteve-se produção de massa seca de 7,07 $\mathrm{Mg} \mathrm{ha}^{-1}$ valor abaixo do observado por Torres (2005), que obteve produção de 10,3 $\mathrm{Mg} \mathrm{ha}{ }^{-1}$. Entretanto, resultados semelhantes foram observados por Nunes et al. (2007), o qual obteve produção de $14,0 \mathrm{Mg} \mathrm{ha}^{-1}$. O valor de massa seca para ervilhaca-peluda $2,55 \mathrm{Mg}$ ha- ${ }^{1}$ foi próximo dos valores obtidos por Giacomini et al. (2003) e Aita e Giacomini (2003), de 2,27 Mg ha- ${ }^{1}$ e 2,66 Mg ha${ }^{1}$, respectivamente e menor quando comparado com resultados obtidos por Penteado (2007) de 4,0 a 6,0 $\mathrm{Mg} \mathrm{ha}^{-1}$.
Com relação à testemunha, ou seja, vegetação espontânea foi encontrado $2,68 \mathrm{Mg}_{\text {ha- }}{ }^{1}$ de massa seca, superior ao valor encontrado por Noce (2008), que obteve produções de $1,61 \mathrm{Mg}^{\text {ha- }}{ }^{1}$ de massa seca de plantas daninhas.

A baixa produção de massa seca obtida em todos os tratamentos deve estar relacionada ao fato de que após a semeadura houve um déficit hídrico, prejudicando o desenvolvimento inicial das culturas e também pela ocorrência de geada, que afetou, principalmente, a cultura do milheto. A ervilhaca peluda visualmente não apresentou nenhum sintoma de injúria deste fenômeno, por ser mais resistente a baixas temperaturas.

Os resultados para densidade global não apresentaram diferenças significativas (Tabela 3).

Michelon, Carlesso e Petry (2007) afirmam que quando a densidade do solo for superior a $1,30 \mathrm{~g}$ $\mathrm{cm}^{-3}$, diferentemente do obtido no presente trabalho, deve-se usar práticas de cultivo que favoreçam o crescimento do sistema radicular e reduzam a densidade. 
Tabela 3. Resultados médios para densidade global do solo em duas profundidades: $0-10 \mathrm{~cm}$ e 10-20 cm.

\begin{tabular}{ccc}
\hline \multirow{2}{*}{ Tratamentos } & \multicolumn{3}{c}{ Densidade global $\left(\mathbf{g ~ c m}^{-3}\right)$} \\
\cline { 2 - 3 } & $\mathbf{0 - 1 0} \mathbf{~ m ~}$ & $\mathbf{1 0 - 2 0} \mathbf{~ c m}$ \\
\hline Ervilhaca & $0,97 \mathrm{a}$ & $1,05 \mathrm{a}$ \\
Milheto & $0,98 \mathrm{a}$ & $0,85 \mathrm{a}$ \\
Testemunha & $0,83 \mathrm{a}$ & $0,76 \mathrm{a}$ \\
\hline CV $(\%)$ & 11,42 & 32,41 \\
\hline
\end{tabular}

${ }^{1}$ Médias seguidas da mesma letra na coluna não diferem entre si pelo teste de Tukey a $5 \%$.

As práticas de manejo tem maior impacto sobre as propriedades físicas de solos arenosos do que solos argilosos. Neste experimento, cujo solo é de textura argilosa, nenhuma camada apresentou densidade superior ao valor crítico propostos por Michelon, Carlesso e Petry (2007), mostrando que o solo apresentava condições favoráveis para o desenvolvimento vegetal.

O sistema de plantio direto, ao manter altas quantidades de resíduos na superfície do solo, proporciona diminuição da densidade. Entretanto, anos de cultivo sob o sistema de plantio direto podem compactar a camada superficial, por não apresentar revolvimento do solo, o que poderia explicar valores maiores na profundidade de 00-10 $\mathrm{cm}$.

Não houve diferenças significativas em relação ao número de plantas daninhas encontradas nos diferentes tratamentos aos 30, 60 e 90 dias após a dessecação (Tabela 4).

Tabela 4. Número de plantas daninhas presentes nos tratamentos testemunha, milheto e ervilhaca aos 30, 60 e 90 dias após dessecação da área experimental.

\begin{tabular}{cccc}
\hline \multirow{2}{*}{ Variável Analisada } & \multicolumn{3}{c}{ Dias } \\
\cline { 2 - 4 } & $\mathbf{3 0}$ Dias & $\mathbf{6 0}$ Dias & 90 Dias \\
\hline $1^{\mathrm{a}}$ Contagem (Testemunha) & $5,25 \mathrm{a}$ & $6,50 \mathrm{a}$ & $9,75 \mathrm{a}$ \\
$2^{\mathrm{a}}$ Contagem (Testemunha) & $6,00 \mathrm{a}$ & $6,50 \mathrm{a}$ & $7,00 \mathrm{a}$ \\
\hline $1^{\mathrm{a}}$ Contagem (Ervilhaca) & $7,50 \mathrm{a}$ & $5,50 \mathrm{a}$ & $5,00 \mathrm{a}$ \\
$2^{\mathrm{a}}$ Contagem (Ervilhaca) & $5,00 \mathrm{a}$ & $5,00 \mathrm{a}$ & $4,50 \mathrm{a}$ \\
\hline $1^{\mathrm{a}}$ Contagem (Milheto) & $7,00 \mathrm{a}$ & $4,50 \mathrm{a}$ & $3,00 \mathrm{a}$ \\
$2^{\mathrm{a}}$ Contagem (Milheto) & $6,00 \mathrm{a}$ & $4,00 \mathrm{a}$ & $3,00 \mathrm{a}$ \\
\hline $\mathrm{CV}\left(1^{\circ}\right) \%$ & & 75,92 & \\
$\mathrm{CV}\left(2^{\circ} \%\right.$ & 41,97 &
\end{tabular}

${ }^{1}$ Médias seguidas pela mesma letra na linha não diferem entre si pelo teste de Tukey a $5 \%$.

$\mathrm{O}$ alto coeficiente de variação obtido na densidade das plantas daninhas é resultante da distribuição irregular destas plantas, possivelmente reduzido com o aumento da área amostrada. Neto (2006) relata que a densidade de plantas daninhas é um parâmetro que quando utilizado isoladamente, não representa com precisão a população de plantas daninhas em determinadas áreas, confirmando os resultados obtidos.

Verificou-se visualmente que a emergência das plantas daninhas foi menor nas coberturas de milheto seguido da ervilhaca peluda por ter uma elevada taxa de decomposição. Ao todo foram identificadas 10 espécies de plantas invasoras na área, com auxílio do manual de identificação de Lorenzi (2000) (Tabela 5).

As análises químicas do solo mostraram diferenças em relação aos tratamentos (Tabela 6). $\mathrm{Na}$ área utilizada com milheto observa-se a maior 
quantidade de potássio $(\mathrm{K})$ na camada $00-10 \mathrm{~cm}$ em comparação a de $10-20 \mathrm{~cm}$ enquanto que, na profundidade de $10-20 \mathrm{~cm}$, foram observados maiores teores de potássio e matéria orgânica (MO) em milheto quando comparado aos demais tratamentos.

Tabela 5. Plantas identificadas nos tratamentos testemunha (vegetação espontânea), milheto e ervilhaca durante condução do experimento.

\begin{tabular}{ccc}
\hline Família & Nome Científico & Nome Comum \\
\hline Amaranthaceae & Amaranthus spp. & Caruru \\
Compositae & Bidens pilosa & Picão preto \\
Compositae & Conyza bonariensis & Buva \\
Compositae & Emilia sonchifolia & Falsa serralha \\
Compositae & Sonchus oleraceus & Serralha \\
Convolvulaceae & Ipomoea grandifolia & Corda-de-viola \\
Crucífera & Raphanus raphanistrum & Nabiça \\
Euphorbiaceae & Euphorbia heterophylla & Leiteiro \\
Poaceae & Brachiaria decumbens & Capim braquiária \\
Rubiaceae & Richardia brasiliensis & Poaia branca \\
\hline
\end{tabular}

Fonte: O Autor

Tabela 6. Análise química do solo, apresentando os macroelementos, nas profundidades 00-10 e 10-20 cm.

\begin{tabular}{|c|c|c|c|c|c|c|c|c|}
\hline Espécie & $\begin{array}{c}P \\
\mathbf{m g ~ d m ^ { 3 }} \\
\end{array}$ & $\begin{array}{c}\text { M.O } \\
\mathrm{g} \mathrm{dm}^{3}\end{array}$ & pH & $\mathbf{H}+\mathbf{A} \mathbf{l}^{3+}$ & $\begin{array}{l}\mathrm{Ca}^{2+} \\
-\mathrm{Cmo} \\
\end{array}$ & $\mathbf{A l}^{3+}$ & $\mathbf{M g}^{2+}$ & $\mathbf{K}^{+}$ \\
\hline \multicolumn{9}{|c|}{ Profundidade $00-10 \mathrm{~cm}$} \\
\hline Testemunha & 29,84 & 35,77 & 4,82 & 5,20 & 6,98 & 0,09 & 2,62 & 0,40 \\
\hline Milheto & 24,63 & 33,24 & 4,95 & 6,14 & 7,05 & 0,10 & 3,11 & 0,55 \\
\hline Ervilhaca & 36,72 & 37,34 & 5,13 & 5,49 & 7,31 & 0,04 & 3,18 & 0,50 \\
\hline \multicolumn{9}{|c|}{ Profundidade $10-20 \mathrm{~cm}$} \\
\hline Testemunha & 18,33 & 29,25 & 4,93 & 6,19 & 5,63 & 0,04 & 2,59 & 0,23 \\
\hline Milheto & 20,48 & 36,21 & 4,95 & 6,14 & 5,08 & 0,03 & 2,64 & 0,30 \\
\hline Ervilhaca & 25,21 & 30,68 & 4,83 & 6,60 & 5,40 & 0,13 & 2,69 & 0,23 \\
\hline
\end{tabular}

* $\left(\mathrm{P}, \mathrm{K}^{+}\right)$e C; $\left(\mathrm{Ca}^{2+}, \mathrm{Mg}^{2+}\right.$ e $\left.\mathrm{Al}^{3+}\right) ;\left(\mathrm{pH} \mathrm{em} \mathrm{CaCl}{ }_{2} 0,01 \mathrm{~mol} \mathrm{~h}^{-3}\right)$

Responsável técnico: Jorge Neumann (Químico - CRQ 09100693-IXR)

Os resultados apresentados estão em conformidade com o relatado por Penteado (2007), que cita que o milheto tende a acumular alta quantidade de potássio na parte aérea da planta, podendo ocorrer maior concentração de potássio disponível nas camadas superficiais dos solos, apresentando maiores concentrações desse nutriente próximo às plantas.

Com relação à ervilhaca peluda, observou-se maior quantidade de matéria orgânica, explicados pela rápida decomposição, como também de fósforo
$(\mathrm{P})$, cálcio $(\mathrm{Ca})$ e magnésio $(\mathrm{Mg})$ na profundidade 00-10 cm. Para a camada de 10-20 cm, o fósforo e magnésio além do alumínio $\left(\mathrm{Al}^{3}\right)$ tiveram maiores valores.

$\mathrm{O}$ alto valor de $\mathrm{P}$ na cultura da ervilha peluda é resultado da quantidade de matéria orgânica e do não revolvimento do solo, promovendo as formações de sítios de P. Estes promoverão a acumulação de $\mathrm{P}$, proporcionando a redistribuição de formas orgânicas e microbianas, tornando-se menos suscetível à adsorção. $\mathrm{O}$ milheto, tendo um 
sistema radicular fasciculado, favorece a diluição do efeito localizado do P.

A diferença dos valores obtidos entre ervilhaca e milheto deve-se principalmente pela diferença do tempo da decomposição e da relação $\mathrm{C} / \mathrm{N}$ das gramíneas e leguminosas. $\mathrm{Na}$ testemunha ou vegetação espontânea, foram observados valores inferiores em todos os nutrientes avaliados com exceção ao cálcio na profundidade $10-20 \mathrm{~cm}$, por apresentarem alta rusticidade às plantas daninhas, possuindo elevada capacidade de absorção de nutrientes.

Para os micronutrientes, o cobre $(\mathrm{Cu})$ teve maiores valores nos tratamentos da testemunha em ambas profundidades e o ferro $(\mathrm{Fe})$ no milheto apresentou os melhores resultados nas duas camadas. $\mathrm{Na}$ testemunha e ervilhaca foram observados maiores valores de manganês (Mn) em ambas profundidades, cujo que para o zinco $(\mathrm{Zn})$ pode ser observado no milheto 00-10 cm e na ervilhaca-peluda em 10-20 cm obtiveram os melhores resultados (Tabela 7).

Tabela 7. Análise química do solo, microelementos, nas profundidades de 00-10 cm e 10-20cm.

\begin{tabular}{ccccc}
\hline Espécie & $\mathbf{C u}$ & $\begin{array}{c}\mathbf{Z n} \\
\mathbf{m g . d m}^{3}\end{array}$ & Fe & Mn \\
\hline Pestemunha & 15,6 & Profundidade 00-10cm & 224,29 \\
Milheto & 13,70 & 5,34 & 85,28 & 223,50 \\
Ervilhaca & 10,98 & 12,13 & 89,05 & 191,34 \\
\hline \multicolumn{5}{c}{ Profundidade 10-20cm } \\
\hline Testemunha & 15,12 & 3,71 & 79,23 & 108,79 \\
Milheto & 10,19 & 12,07 & 76,37 \\
Ervilhaca & 6,87 & 14,18 & 70,92 & 112,85 \\
\hline
\end{tabular}

Mehlich 1 e Gravimetria; Cloreto de Potássio $1 \mathrm{M}$; Mehlich Responsável técnico: Jorge Neumann (Químico - CRQ 09100693-IXR)

Comparando-se a análise química antes da implantação do experimento (Tabela 1), observase que houve leve acidificação do solo e aumento dos principais nutrientes o mesmo ocorrendo com relação aos micronutrientes.

Com esses resultados pode-se afirmar que tanto a ervilhaca-peluda como o milheto apresentaram bom resultado comparado com a testemunha, diferenciando-se em alguns nutrientes. Para determinar o melhor tratamento deve-se saber qual a cultura a ser implantada posteriormente. No caso do milho o mais recomendado seria a ervilhaca peluda por fixar maior quantidade de N. Enquanto que na soja, que não necessita de $\mathrm{N}$ na adubação pelo fato de ser leguminosa fixadora de $\mathrm{N}$, poderia ser recomendado o milheto por ter apresentado elevada taxa de K e uma boa produção de massa seca.

\section{Conclusões}

Dentre as plantas de cobertura avaliadas, o milheto foi o que apresentou maior quantidade de matéria seca, que juntamente com a ervilhaca peluda promoveu melhoria química do solo, diferenciando-se da testemunha, sendo, portanto ambos considerados como alternativas para a melhoria das condições gerais do solo da região.

Os tratamentos não interferiram significativamente na densidade global do solo.

\section{Referências}

AITA, C.; GIACOMINI, S. J. Decomposição e liberação de nitrogênio de resíduos culturais de plantas de cobertura de solo solteiras e consorciadas. Revista Brasileira de Ciência do Solo, Viçosa, MG, v. 27, n. 4, p. 601-612, 2003. 
AITA, C.; GIACOMINI, S. J.; HÜBNER, A. P.; CHIAPINOTTO, I. C.; FRIES, M. R. Consorciação de plantas de cobertura antecedendo o milho em plantio direto. Revista Brasileira de Ciência do Solo, Viçosa, MG, v. 28, n. 4, p. 739-749, 2004.

DUARTE, J. B. J. Avaliação agronômica da canade-açúcar, milho e feijão em sistema de plantio direto em comparação ao convencional em Campos dos Goytacazes - RJ. 2006. Tese (Doutorado em Agronomia / Produção Vegetal) - Centro de Ciências e Tecnologias Agropecuárias. Universidade Estadual do Norte Fluminense Darcy Ribeiro, Campos dos Goytacazes.

EMPRESA BRASILEIRA DE PESQUISA AGROPECUÁRIA - EMBRAPA. Centro Nacional de Pesquisa de Solos (Rio de Janeiro, RJ). Manual de métodos de análise de solo. Rio de Janeiro: EMBRAPA, 1997. $212 \mathrm{p}$.

Sistema brasileiro de classificação de solos. 2.ed. Rio de Janeiro: EMBRAPA, 2006. 306 p.

FEDERAÇÃO BRASILEIRA DE PLANTIO DIRETO NA PALHA - FEBRAPDP. Brasil. Evolução da área cultivada em plantio direto. 2004. Disponível em:

$<$ ht t p ://www.febrapdp.org.br/download/ BREvolucaoPD92a02.pdf>. Acesso em: 12 out. 2008.

GIACOMINI, S. J.; AITA, C.; VENDRUSCOLO, E. R. O.; CUBILlA, M.; NICOLOSO, R. S.; FRIES, M. R. Matéria seca, relação $\mathrm{C} / \mathrm{N}$ e acúmulo de nitrogênio, fósforo e potássio em misturas de plantas de cobertura de solo. Revista Brasileira de Ciência do Solo, Viçosa, MG, v. 27, n. 2, p 325-334, 2003.

LORENZI, H. Manual de identificação e controle de plantas daninhas: plantio direto e convencional. Nova Odessa: [s.n.], 2000. 336 p.

MICHELON, C. J.; CARLESSO, R.; PETRY, M. T. Qualidade física de solos irrigados do Estado do Rio Grande do Sul. Programa de pós-graduação em ciência do solo, Universidade Federal de Santa Maria (UFSM), Santa Maria, RS. Ciência Rural, Santa Maria, v. 37, n. 5, set./out. 2007.

MOREIRA, F. M. S.; SIQUEIRA, J. O. Microbiologia e bioquímica do solo. Lavras: UFLA, 2002. 626 p.

NEGRINI, A. C. A. Desempenho da alface (Lactuca sativa L.) consorciada com diferentes adubos verdes. Piracicaba, 2007. Disponível em: <www.teses.usp.br/ teses/disponiveis/11/11136/tde-08082007-163839/>. Acesso em: 14 set. 2008.

NETO, H. B. Dinâmica populacional de plantas daninhas, desenvolvimento, estado nutricional e produção de citros em função da associação de adubos verde, cobertura morta e herbicidas. 2006. Dissertação (Mestrado em Agronomia) - Escola Superior de Agricultura Luiz de Queiroz, Piracicaba. Disponível em: <http:/www. teses.usp.br/teses/disponiveis/11/11136/tde-07032007145635/>. Acesso em: 15 set. 2008.

NOCE, M. A. Interferência de palhada de sorgo, capim braquiária e milheto sobre a cultura do milho e plantas daninhas. 2008. Dissertação (Mestrado em Fitotecnia) Departamento de Agronomia. Universidade Federal de Lavras, Lavras, MG. Disponível em: <www.sbcpd.org/ congresso/resumos/469.doc $>$. Acesso em: 15 set. 2008.

NUNES, U. R.; SANTOS, N. F.; FARNEZI, M. M. M.; JÚNIOR, V. C. A.; BRANDÃO, D. S.; PEREIRA, G. D. Qualidade fisiológica de sementes de feijão em plantio direto sobre diferentes coberturas de plantas em Diamantina, MG. Ciênc. Agrotec., Lavras, v. 31, n. 6, p. 1737-1743, 2007.

OHLAND, R. A. A.; SOUZA, L. C. F de; HERNANI, L. C.; MARCHETTI, M. E.; GONÇALVES, M. C. Culturas de cobertura do solo e adubação nitrogenada no milho em plantio direto. Ciênc. Agrotec., Lavras, v. 29, n. 3, p. 538-544, maio/jun. 2005.

OLIVEIRA, A. J.; RAIJ, B. V.; ROSAND, P. C.; LOBATO, E. Adubação fosfatada no Brasil: apreciação geral, conclusões e recomendações. Brasília: EmbrapaDID, 1993.

PENTEADO, S. R. Adubos verdes e produção de biomassa melhoria e recuperação dos solos. Campinas: Editora Via Orgânica, 2007. 170 p.

PERIN, A. Desempenho de milho e brócolos em sucessão à adubação verde. 2005. Tese (Doutorado em Fitotecnia) - Departamento de Agronomia. Universidade Federal de Viçosa, Viçosa, MG. Disponível em: <www.cipedya. com/web/FileDownload.aspx?IDFile $=159346>$. Acesso em: 17 set. 2008 .

SAS INSTITUTE. SAS technical report. SAS/STAT software: Changes and Enhancement, Cary NC: SAS Institute. 2006.

SIMEPAR. Contato. 2008. Disponível em: < www. simepar.br>. Acesso em: 05 out. 2008.

SOARES, E. D. R. Endogamia, componentes da variância e heterose em caracteres agronômicos em milheto perola (Pennisetum glaucum, (L) R. Brown). 2005. Tese (Doutorado em Fitotecnia) - Universidade Federal Rural do Rio de Janeiro. Instituto de Agronomia, Seropédica, RJ.

TORRES, J. L. R.; PEREIRA, M. G.; ANDRIOLI, I.; POLIDORO, J. C.; FABIAN, A. J. Decomposição e liberação de nitrogênio de resíduos culturais de plantas de cobertura em um solo de cerrado. Revista Brasileira de Ciência do Solo, Viçosa, MG, v. 29, n.1, p. 609-618, 2005. 